\title{
ENEMIGOS ÍNTIMOS O VECINOS DISTANTES. La antropología y los estudios culturales en el Ecuador
}

\author{
Xavier BRITO ALVARADO \\ Universidad Central del Ecuador \\ xavibrial@yahoo.com.ar
}

\begin{abstract}
INTIMATE ENEMIES O DISTANT NEIGHBORS. Anthropology and cultural studies in Ecuador
\end{abstract}

Resumen: La Antropología y los Estudios Culturales han mantenido una serie de disputas, tanto en el orden conceptual como metodológico. Estos dos campos del saber parecerían que tienen más puntos de encuentro que distancias; comparten una serie de autores y teorías, que permiten construir conectores comunes. Sin embargo, en Ecuador estas disputas se han institucionalizado alrededor de las dos universidades de mayor prestigio, donde las disputas parecerían que se tornan más enraizadas. Este ensayo pretende dar a conocer los recorridos históricos de estos dos campos del saber en Ecuador, así como de las disputas y semejanzas teóricas existentes.

Abstract: Anthropology and Cultural Studies have been maintaining a series of disputes, conceptual and methodological. However, these two fields of knowledge seem to have more closeness: share authors and theories that allow building common connectors. These disputes in Ecuador have been institutionalized around the two most prestigious universities; where them seem to become deepest. This paper seeks to highlight the historical tours of these two fields of knowledge in Ecuador, and other disputes and existing theoretical similarities.

Palabras clave: Antropología. Estudios Culturales. Cultura. Hegemonía. Ecuador Anthropology. Cultural Studies. Culture. Hegemony 


\title{
I. Primer contacto: abriendo la cortina del debate
}

\begin{abstract}
Tanto la Antropología como los estudios culturales han tenido que luchar constantemente contra sus propios demonios.
\end{abstract}

Peter Wade

Pocos conceptos o disciplinas, en Ciencias Sociales, han sido tan controversiales como los Estudios Culturales, controversias que en gran medida han estado marcadas por las disputas hegemónicas e ideológicas del conocimiento, especialmente desde la Antropología. Mucha tinta se ha utilizado para escribir las distancias, las críticas y los acercamientos entre estos dos campos del saber. Sin duda, el punto neurálgico que ha marcado las diferencias lo constituyen los conceptos y metodologías utilizadas.

La producción sobre la teorización de los procesos culturales en nuestro país, a pesar de ser todavía incipiente, evidencia la existencia de disputas académicas que han dibujado una ruta de conocimientos lleno de discursos, que en parte han conducido a un alejamiento de la realidad nacional.

En Ecuador, las disputas epistemológicas sobre la cultura, y todo lo que engloba el concepto, se encuentran marcadas por los discursos provenientes de la Antropología y los Estudios Culturales, disputas que en muchas ocasiones trascienden el campo epistemológico y se concentran en un debate institucional y político. Dos de las instituciones de postgrado más importantes del país, en materia de Ciencias Sociales, la Universidad Andina Simón Bolívar, UASB, en Estudios Culturales y la Facultad Latinoamérica de Ciencias Sociales, FLACSO, en Antropología, han encabezado el panorama descrito.

"Este ensayo se divide en dos espacios, el primero aborda la historia y las disputas hegemónicas por el objeto, la cultura, y el conocimiento entre la Antropología y los Estudios de la Cultura; que a su vez permiten abrir una segunda discusión sobre el panorama de apropiaciones, producciones y circulación de conocimientos en el Ecuador, más aún en tiempos donde la educación superior en el país se encuentra en un proceso de cambios, no solo de forma sino de fondo; donde la producción de conocimientos, vía maestrías y doctorados, se ha convertido en factor determinante para quienes ambicionan formar parte del sistema educativo superior Para empezar recordemos lo que Peter Wade nos indica sobre estas disputas a las cuales no se puede pasar podemos pasar por altoTanto los estudios culturales y la antropología han estado involucrados en los procesos de crítica auto-reflexiva...Si la antropología puede interactuar con los estudios de la cultura para dotarlos de más sentido crítico y de mundo, entonces esta es una buena razón para dejar de ver los dos campos como contrincantes en una competencia de todo o nada" (Wade, 2001: 15-23).

Esta aseveración podría abrir caminos menos tortuosos para encontrar un punto en común entre estos dos campos de saberes.

\section{El recorrido histórico de la antropología}

Todo recorrido académico tiene un punto de partida que nos aviva a reflexionar sobre su origen. Muchas veces la historia de las disciplinas nos indica el camino de su futuro, sus luchas por reivindicar su origen o tal vez para aproximarse a una crítica propia de su existencia. La Antropología ha tenido un sesgo muy controversial debido a la forma en que se estableció como disciplina, en pleno contexto de expansión colonial europea sobre África, 
América y Asia, la que muchos teóricos sociales han enfilado sus más duras críticas, colocando a la Antropología como una disciplina funcional a los intereses de la colonización. "La relación colonial instaura no solo un régimen de poder administrativo y militar, sino un régimen de verdad que sustenta las prácticas de subordinación de espacios, poblaciones y saberes" (Rojas, 2011: 73). Frente a esta aseveración Wade argumenta:

"La antropología se formó de forma menos crítica y dentro de un contexto colonial. La idea de la antropología como la dama de compañía del colonialismo no aguanta ni el más mínimo examen y los antropólogos eran "imperialistas arrepentidos" y a menudo "tipos extraños y hasta maniáticos". Aun así, no cabe duda de que la antropología carga las maracas de su cuna colonial" (Wade, 2011: 20).

Un punto a favor para la terminación de las críticas hacia la Antropología por su origen, es el de Nigel Rapoort, quien abarca el concepto mucho más allá del contexto histórico.

"La antropología es el estudio de la construcción humana del mundo, una conciencia de la creatividad, de la individualidad, de la sociabilidad, y de la historicidad de esa construcción, y una actitud de ironía con respecto al absolutismo y a la finalidad de cualquier construcción particular" (Rapoort, 2011: 41).

Las limitaciones históricas-políticas que aún pretenden endosar a esta disciplina poseen profundas grietas conceptuales, ya que la Antropología ha podido combatir a sus demonios y ha creado nuevos espacios de conocimientos. En este sentido, George W. Stocking describe lo que podría llamarse nuevos escenarios antropológicos.

"Las fronteras de la antropología siempre han sido problemáticas; quizá aún más que las de otras disciplinas o discursos de las ciencias sociales. No obstante, nunca fueron tan problemáticas como lo son hoy en día. Un reciente número de Anthropology Newsletter sugiere algunas dimensiones y dinámicas del problema de las fronteras. Desde 1983, cuando la American Anthropological Association fue reorganizada para representar de manera más efectiva las numerosas "antropologías de adjetivo" que habían surgido durante el cuarto de siglo anterior, el número de unidades de la asociación reconocidas constitucionalmente era más del doble. Ahora hay quince "sociedades" subsidiarias (incluyendo la etnológica, humanística, lingüística, médica, psicológica, urbana, visual, latinoamericana y europea, así como aquellas dedicadas a la "consciencia" y al "trabajo"); diez "asociaciones" (incluyendo africanistas, blancos, feministas, política y jurídica, tercera edad y estudiantes, así como varias asociaciones regionales y una dedicada a la "práctica de la antropología"); tres "consejos" (educación, museos, nutrición); dos "secciones" (biología y arqueología); y una agrupación no categorizada llamada simplemente "cultura y agricultura". Finalmente, existe una unidad dedicada a la "antropología general"- rúbrica que en un tiempo podía haber incluido a todo el resto, pero cuyo actual estatus residual está apropiadamente señalado por su denominación como "división"-. Reflejando esta fragmentación subdisciplinaria" (Stocking, 2002: 11).

La historia de la Antropología como disciplina tiene un tinte curioso, muy parecido a los Estudios Culturales, nació como campo de estudio adjunto a departamentos históricos o lingüísticos de las más prestigiosas universidades norteamericanas. En el contexto latinoamericano la Antropología comenzó a institucionalizase en la primera mitad del siglo XX, bajo el paraguas del Indigenismo que tenía como base teórica el evolucionismo enmarcado en la idea de la integración nacional de aquellas culturas que fueron sometidas al dominio colonizador, en palabras de Carlos Iván Degregori. 
"En el caso peruano lo mejor de la antropología contribuyó a ampliar la foto de familia, a transformar la comunidad imaginada llamada Perú. El país concebido en un principio para sus élites como occidental y criollo, fue cediendo así paso a otro más contradictorio pero también más plural. El aparte central de la antropología en sus primeras décadas (1940-1960) fue contribuir a la articulación nacional mediante las monografías etnográficas, explorando territorios ignotos tanto en el sentido literal y geográfico de la palabra, como también metafórico: incursionando en ámbitos socioculturales y temporales desconocidos" (Degregori, 2007: 302).

El mismo autor amplía su explicación sobre la Antropología y el Indigenismo como el motor para emprender una larga lucha de reivindicación del otro Perú y por qué no pensar en el resto de países de la región. "Desde fines del siglo diecinueve y durante la primera mitad del siglo veinte, el indigenismo como reivindicación del "indio actual" y de su incorporación como base fundamental de la "comunidad imaginada" peruana se abrió campo, con altibajos, en la conciencia, la cultura y la políticas peruanas" (Degregori, 2007: 306).

La institucionalización de la Antropología en la academia latinoamericana y ecuatoriana, posee una trayectoria consolidada e institucionalizada. Esteban Krontz argumenta "Desde mediados del siglo pasado, de modo aproximadamente paralelo al proceso de descolonización formal de muchos países asiáticos y africanos, se ha gestado un cambio profundo en la antropología mundial" (Krotz, 2001: 10).

En América Latina hay una larga lista de instituciones colaboradoras en Antropología entre las que se pueden citar: Red de Antropologías del Mundo, Red Latinoamericana de Antropología Jurídica, Asociación de Antropólogos Iberoamericanos en red-AIBR, A Associação Brasileira de Antropologia, La Asociación Latinoamericana de Antropología, La Asociación Latinoamericana de Antropología Forense, Asociación Latinoamericana de Antropología, entre otras.

En el espacio académico ecuatoriano la Antropología tiene una presencia fuerte dentro de una comunidad investigativa, tanto en las universidades como en organismos que aglutinan a los antropólogos/as creando redes de participación; a esto hay que añadir una producción académica que ha permanecido en constante crecimiento, en gran medida este fortalecimiento del que hacer antropológico ha estado mediado por los nuevos panoramas sociales. La implementación de la Antropología como disciplina académica se remonta a 1971 cuando se crea el Departamento de Antropología en la Pontificia Universidad Católica del Ecuador, PUCE. Luego en el año de 1981, la Escuela Superior Politécnica del Litoral, ESPOL crea la Escuela Politécnica de Arqueología, la que se transformó en el Centro de Estudios Arqueológicos y Antropológicos de la misma. En el Ecuador, la Antropología tiene un fuerte espacio investigativo en organismos no universitarios, tal vez los más representativos constituyen los museos del Banco Central del Ecuador y el Instituto Otavaleño de Antropología. En la actualidad, la Antropología tiene tres instituciones universitarias, a nivel de pregrado: la Pontificia Universidad Católica del Ecuador, PUCE, la Universidad Politécnica Salesiana, UPS, y La Universidad San Francisco de Quito, USFQ, como curiosidad todas existentes en Quito. Una a nivel de postgrado: la Facultad Latinoamericana de Ciencias Sociales, FLACSO. En este sentido, hay que señalar que el desarrollo de la Antropología en Ecuador ha estado atravesado por los debates surgidos en países cercanos como lo argumenta Fernando García.

"La situación de los centros de formación antropológica con que cuenta el país muestra parcialmente el proceso histórico vivido por la disciplina y da cuenta del surgimiento del pensamiento antropológico ecuatoriano, como parte de las denominadas antropologías del Sur (Krotz, 1993) o periféricas (Cardoso, 
1998), que se inscriben en la corriente iniciada por un conjunto de antropólogos provenientes de lugares que no son considerados centros de elaboración del pensamiento antropológico, entre ellos los latinoamericanos, que están empeñados en pensar las denominadas antropologías del mundo (Lins Ribeiro y Escobar, 2008) y no una antropología universal, como un forma de recuperar uno de los ejes sobre los cuales ha girado la antropología como ciencia, la diversidad tanto científica como conceptual" (García, 2011: 1-2).

En este sentido, García retoma las ideas de Krotz al decir que la Antropología ecuatoriana debe seguir los pasos del resto de América Latina. El aprender de las lecciones "es mirar no sólo hacia Europa y Estados Unidos para generar teoría antropológica, sino a América Latina para que podamos iniciar un gran ejercicio propio también de la antropología, de comparación y de sistematización de nuestra realidad" (García, 2011: 68).

Este repaso pequeño de la Antropología y sus avatares para consolidarse como disciplina científica, refleja que la propia historia, de las disciplinas, es capaz de articular nuevos discursos, tanto para aprenden de sus errores como para realizar un auto-juzgamiento para encontrar una nueva lectura.

\section{La historia continúa, los estudios culturales}

"En la actualidad la elección de entrar en el ámbito de los Estudios Culturales se caracteriza por ser un tanto peligrosa, si no maldita. Parece ser que los Estudios Culturales...se han convertido en una amenaza" (Grossber, 2010: 55). Esta idea es una invitación, entre aterradora y excitante, para comprender de qué se trata los Estudios Culturales.

Los Estudios Culturales o "Cultural Studies" nacen en Inglaterra en el período de la segunda postguera mundial, una época caracterizada por cambios políticos en Europa occidental. "Los estudios culturales tienen un claro y único origen en las actividades intelectuales y en los personajes asociados al CCCS [Universidad de Birmingham] Para ellos, los nombres de Richard Hoggart, Raymond Williams, E. P. Thompson y, posteriormente, Stuart Hall corresponden a una especie de 'padres fundadores' de los estudios culturales" (Restrepo, 2012: 8).

Una buena genealogía "epistemológica" de los Estudios Culturales, que va mucho más allá de las fechas, sino que devela la política de esta nueva esfera de conocimiento, es la propuesta por John Beverley:

"La escuela de Birmingham tenía dos componentes teóricos: uno era el tipo de trabajo que hacían los historiadores asociados al marxismo inglés, por ejemplo el libros esencial de E.P. Thompson, The Making of the English Working Class, o la sociología desarrollada durante el período de gobierno del Partido Laborista, representada sobre todo por Raymond Williams" (Beverley, 1996: $71)$.

Se puede argumentar que esta época estuvo marcada, entre otros contextos, por: un acceso de la población pobre a la educación en especial a las universidades, las mujeres comenzaron a reclamar y crear espacios de poder y reivindicación social, de igual manera, grupos étnicos como los "negros", las minorías sexuales comenzaron abrirse un espacio dentro de la sociedad y el inicio de la extraordinaria penetración en la población de las tecnologías de la información. A continuación, dos ideas que pueden iluminar el contexto social y político del nacimiento de los Estudios Culturales.

"Bajo el interés común por la cultura inglesa, y la manera como esta excluía 
y descalificaba a la cultura popular, un grupo de teóricos comenzaron sus indagaciones entre la clase obrera y los institutos de educación para adultos, en los que dictaban clases. Es así que en 1957 Richard Hoggart, profesor de literatura inglesa, publicó su libro "The uses of Literacy: Aspects of WorkingClass Life with Special Referentes to Publications and Entertainments" (1957), donde analizaba el poder de los medios en la cultura y la cotidianidad de la clase obrera inglesa. Por su parte, Raymond Williams escribió "Culture and Society" (1958), y "The Long Revolution" (1961), ambos textos basados en tradiciones marxistas. Williams entendía a la cultura como una entidad global, que evidenciaba regímenes y sistemas de percepción, y veía el surgimiento y evolución hacia una "cultura humana general" moldeada por dichos sistemas" (Auza, 2012: 2-3).

Para Mattelart y Neveu, la historia de los Estudios Culturales ha pasado por una serie de etapas ideológicas.

"Desde el marxismo althuseriano hasta la semiología, los miembros del centro
han compartido una común atracción por lo que el establishment universitario
considerada entonces, en el mejor de los casos, como un pintoresco
vanguardismo, y en el peor como el "opio de los intelectuales" Este interés
por la renovación de las herramientas del pensamiento crítico jamás viró a
la ortodoxia. El centro fue un caldo de cultivo de importaciones teóricas, de
chapuzas innovadoras sobre cuestiones hasta entonces consideradas indignas
del trabajado académico" (Mattelart, Neveu, 2003: 47-48).

Ya, en su concepción teórica los Estudios Culturales se conciben o pretenden presentarse, como un gran proyecto intelectual destinado a la creación de una serie de cuestionamientos sobre las conceptualizaciones de la cultura, poder y otras cuestiones epistemológicas.

En las primeras investigaciones de los Estudios Culturales la aproximación marxista estaba presente; los estudios de los medios de comunicación y su impacto en las clases marginales, las culturas juveniles, las subculturas y la literatura constituían los títulos más importantes, incluso hoy en día son temas de referencia.

Los Estudios Culturales poco a poco comenzaron a migrar de Inglaterra, en 1990 comienza su rápida y conflictiva internacionalización en América, Restrepo señala: "El seminario (Cultural Studies Now and in the Future) realizado en abril de 1990 en la Universidad de Illinois, Estados Unidos, constituiría uno de los hitos más relevantes en esta internalización y expansión de los estudios culturales" (Restrepo, 2012: 8). Este es el punto de partida para la llegada a América Latina, que se consolidó a medidos de la década de los noventa. La vía de llegada fueron los estudios de la Comunicación, especialmente los desarrollados por Jesús Martín-Babero y Néstor García Canclini, este último aclamado como uno de los exponentes máximos de los Estudios Culturales Latinoamericanos, en este contexto Daniel Mato argumenta:

"Desde hace poco menos de una década asistimos en América Latina a un proceso acelerado de institucionalización de eso que algunos colegas latinoamericanos han comenzado a llamar "Estudios culturales latinoamericanos". Este proceso viene ocurriendo en diálogo y relación, y a veces también como consecuencia, del proceso de institucionalización de lo que nuestros colegas que trabajan en universidades de Estados Unidos, Inglaterra y Australia llaman en inglés Cultural Studies y de lo que algunos de ellos de manera complementaria denominan Latin American Cultural Studies” (Mato, 2002: 26). 
Conceptualizando, se puede comprender a los Estudios Culturales como una esfera de conocimientos que pretenden comprender y reflexionar a la cultura a partir de prácticas sociales. No obstante, los Estudios Culturales Latinoamericanos poseen una característica singular, en este sentido, podemos visibilizar una realidad histórica presente pero que nadie ha querido ver.

"Los estudios culturales latinoamericanos son, a nuestro entender, un campo de reflexión configurado desde la tradición crítica latinoamericana, que se mantiene en diálogo constante, muchas veces conflictivo, con escuelas de pensamiento occidentales como lo son el estructuralismo francés, el pos-estructuralismo y el posmodernismo; la lingüística, la antropología y la sociología de la cultura; la escuela de Frankfurt y la teoría de la recepción; la semiótica y el feminismo; y, más recientemente, los estudios culturales en sus vertientes angloamericanas. Paralelamente, la larga e importante tradición del ensayo de ideas en América Latina tiene mucho que ver con el trabajo que comienza con Bello y Sarmiento y aún no termina, sin descartar los presupuestos encerados en tendencias criticoteóricas tan importantes como la crítica de la dependencia, la pedagogía del oprimido, la teología de la liberación o las teorías atinentes a la problemática cultural, como la transculturación o la heterogeneidad, variantes particulares más recientes de ese pensamiento" (Trigo, Del Sarto, Ríos, 2003: 324-325).

Ahora algunos conceptos y delimitaciones claves de los Estudios Culturales para comprender su enorme complejidad. Por su parte Nelly Richard argumenta que los Estudios Culturales poseen características muy delimitadas que permiten la construcción de conocimientos, por medio de una lógica transdisciplinar y una crítica al conocimiento eurocéntrico como el único valedero:

"Mezcla de aparatos teóricos (marxismo, semiología, deconstrucción, psicoanálisis, antropología, etc.) que ponen de manifiesto la necesidad de construir los estudios culturales desde las intersecciones, los cruces, los bordes y la imposibilidad de acceder a una totalidad de conocimiento objetivo para "nutrirse de préstamos, de desplazamientos y reconversiones transgenéricas que entrecruzan variados marcos de lectura". Los estudios culturales ofrecen así un nuevo escenario de diálogo crítico entre distintos saberes que son siempre móviles. [...] Rechazo de la división jerárquica entre cultura alta y cultura baja. En este sentido, los estudios culturales se enfrentan radicalmente a la legitimidad del "canon blanco occidental". Esta crítica a las jerarquías de la cultura superior sitúa a los estudios culturales en el ámbito no institucional que es en definitiva quien separa la baja y alta cultura" (Richard, 2005: 456).

Otro concepto sobre los estudios culturales es el que lo da Catherine Walsh, que argumenta que la carga política se convierte en una condición no negociable de los EECC.

"Llamar «estudios culturales» estos esfuerzos de pensar la cultura políticamente como sitio de diferencias, luchas sociales y dejar al descubierto las prácticas y producciones epistemológicas, sociales y culturales y su relación con el poder, podría ser problemático. No obstante, fue con el afán de nombrar e identificar una rúbrica cuyo significado no parta de una singularidad local o regional sino también de la problemática de la totalidad, una manera de articular el trabajo crítico aquí con otros lugares, y construir puentes y articulaciones entre estos proyectos políticos" (Walsh, 2010: 219). 
Una de las críticas hacia los Estudios Culturales, que parten desde la Antropología, es que sus investigaciones han quedado en una retórica de teorías, que tienden a formar una esfera del romanticismo exagerado sobre las condiciones políticas, culturales y que su campo de accionar muchas veces es difuso, donde se entrelazan la literatura, la psicología, la historia y otras disciplinas.

"En general, los Estudios Culturales Latinoamericanos respondieron a una serie de circunstancias entre las que se contaba un desgaste del análisis textual; la sobredimensión del influjo de las industrias culturales -que de alguna manera y según ellos perdía de vista las facultades de las audiencias para resignificar y dar nuevas simbologías a los contenidos-; y en última instancia, la ignorancia sobre las audiencias y los consumidores" (Auza, 2012: 8).

Sin duda, uno de los críticos más recurrentes es el de Carlos Reynoso, quien descalifica el accionar tanto en teoría como metodología a los Estudios Culturales. "Los estudios culturales son un campo de estudios excitante y «caliente» [hot]. Se han convertido en pasión entre los progres de todas las clases. ... Parecen estar por doquier y todo el mundo habla de ellos (Reynoso, 2000: 11). Una crítica proveniente de FLACSO es la del ex coordinador de Antropología Xavier Andrade que argumenta:

"Frecuentemente, discutiendo el tipo de fuentes de teoría antropológica que son citadas o utilizadas por colegas y profesores en Guayaquil, las más frecuentes referencias, cuando no las únicas. Que se inscriben dentro del canon son Néstor García Canclini, quien no es un antropólogo por entrenamiento profesional... guarda una afinidad cercana con discusiones privilegiadas en estudios de la comunicación especialmente en lo concerniente a globalización, nociones de ciudadanía cultural, los «imaginarios», y la «hibridez» que supuestamente definiría la condición urbana de sociedades contemporáneas" (Andrade, 2003: 13).

Precisamente estas críticas han provocado debates profundos entre la Antropología y los Estudios Culturales en Ecuador. En lo que se refiere al panorama institucional de los Estudios Culturales, Mónica Szurmuk y Robert Mckee describen que en la región existe una multiplicación en las ofertas académicas de estos estudios. "Lo cierto es que a principios del siglo XXI, aun cuando los estudios culturales son percibidos como marginales, hay programas en casi todos los países de América Latina que se definen como formaciones de postgrado o de especialización en estudios culturale" (Szurmuk, Mckee, 2009: 57). Genealógicamente estos estudios comenzaron a instalarse en América Latina en los años noventa, en este sentido, Restrepo y Rojas, retoman la idea de Walter Mignolo para argumentar está institucionalización:

"Según Mignolo la institucionalización de los estudios culturales puede obedecer a tres tipos de razones distintas: la razón crítica, la razón instrumental o la razón estratégica. En el primer caso, se trata de aquellos proyectos intelectuales política y éticamente sustentados, que responden a problemas situados; dichos proyectos pueden requerir de un espacio institucional donde realizarse y la escogencia del rubro de estudios culturales responde a que son proyectos que no cabrían dentro de las estructuras universitarias existentes. [...] Pero, la institucionalización de los estudios culturales también puede obedecer a una razón instrumental, en cuyo caso el propósito sería de tipo administrativo, ligado a principios como la eficiencia. Lo que se estaría 
privilegiando no sería un proyecto intelectual sino de capacidad institucional para responder a políticas públicas como las de autofinanciación, que ven en los postgrados una oportunidad de generar recursos propios; situación bastante en boga en las actuales políticas de ciencia y tecnología. En el caso de la razón estratégica, se trataría igualmente de responder a demandas institucionales, esta vez en términos de ventajas comparativas internas o externas, que buscan consolidar el lugar de poder de un proyecto o de la institución en su conjunto" (Restrepo, Rojas, 2003: 35).

En el caso ecuatoriano, los Estudios Culturales carecen de formación en pregrado, la entrada principal es por la vía de la Comunicación Social, autores como Jesús Martín-Barbero, Armando Silva, Aníbal Ford, Carlos Monsiváis, entre otros, son referencias al momento de reflexionar a la cultura, a esto hay que añadirle la fuerte presencia de autores como: Marx, Gramsci, Derrida, Foucault, no en vano:

"Foucault ha sido clave para la construcción de categorías centrales para los estudios culturales. Tal es el caso de conceptos como de articulación y representación, y sus análisis acerca de los medios de comunicación, el multiculturalismo, la ideología y la diáspora". (Rojas, 2011: 76).

En lo referente a estudios de postgrado, la maestría y el doctorado en Estudios Culturales Latinoamericanos de la Universidad Andina Simón Bolívar, son los únicos en el país, este doctorado tiene un enfoque del pensamiento descolonial, al que Mignolo lo define como:

"Los estudios culturales, en la Universidad Andina, se están constituyendo como un lugar institucional que giran en torno a ciertos legados del pensamiento crítico mestizo/inmigrante, incluyendo la colonialidad del poder, Quijano, Filosofía de la liberación, Dussel, colonialismo, Quispe, Macas, pensamiento afro, Cesaire, Fanon" (Mignolo, 2005: 54).

Bajo estas ideas, la Antropología y los Estudios Culturales poseen una disputa sobre el conocimiento, una mirada a la sociedad, las dos se posesionan desde su "locus" de enunciación que difícilmente desean salir. Este acercamiento de la institucionalización nos permite dar el paso hacia los conflictos y tensiones más profundas, sin embargo, la presencia de maestrías en Comunicación y Cultura, en diferentes universidades públicas y privadas, parecen estar más cerca de los Estudios Culturales.

\section{Segundo contacto: la conflictividad, la cultura}

Los procesos de globalización conllevaron a la creación de esferas epistemológicas y metodológicas para entender los nuevos escenarios sociales. Sin duda, la cultura constituye el concepto más controversial, concepto que ha sido reclamado tanto por la Antropología como por los Estudios Culturales, provocando críticas mutuas.

Reynoso, argumenta que "con el advenimiento de los estudios culturales la Antropología crítica integrada a ellos redibujando su linaje. La que se vive hoy es la tercera oleada del criticismo que atraviesa la disciplina" (Reynoso, 2000: 201-202). Pero las críticas de Reynoso llegan a describir a los Estudios Culturales como la sistematización de muchas disciplinas, en una que llega a convertirse en una especie de moda académica.

"Los estudios culturales se encarnan, sin lugar a dudas, el último grito de la moda. Si fuéramos a creer en las afirmaciones posmodernas que cada vez más 
los atraviesan, serían el último grito a secas, en el pleno sentido de la palabra. Constituidos por propia iniciativa en el contenido y la forma del fin de la Historia del milenio, de las ideologías y de las disciplinas, no es de esperarse que después de ellos vuelva a crecer otra hierva teórica que les haga sombra, ni que se erija un nuevo escenario que los deje atrás" (Reynoso, 2000: 9).

Los teóricos de los Estudios Culturales argumentan que constituyen un campo plural de disciplinas, transdisciplinario, de saberes y prácticas intelectuales para reflexionar las articulaciones existentes entre la cultura, poder y política, trilogía que puede ser entendida como: cultura-como-poder y el poder-como-cultura. En palabras de Restrepo "Los estudios culturales constituyen una modalidad de teoría crítica que se toma seriamente la labor investigativa como el mecanismo para comprender mejor los amarres concretos de la cultura y del poder" (Restrepo, 2009: 12).

La cultura es, sin dudas, uno de los conceptos claves para realizar una diferenciación más precisa entre estos dos campos de saberes. En la Antropología, este concepto ha pasado por una serie de fases donde queda marcado por los contextos históricos. Una primera fase llamada visión positivista de la cultura y una segunda marcada por lo lingüístico de cultura. Sin embargo, podemos anclarnos en la definición de cultura dada por Clifford Geertz:

"La cultura se comprende mejor no como complejos de esquemas concretos de conducta - costumbres, usanzas, tradiciones, conjuntos de hábitos- como ha ocurrido en general hasta ahora, sino como una serie de mecanismos de control -planes, recetas, fórmulas, reglas, instrucciones (lo que los ingenieros de computación llaman "programas"- que gobiernan la conducta" (Geertz, 2003: 51).

Esta definición no constituye la única expuesta desde la Antropología, sin embargo, puede ser un referente epistemológico. Para los Estudios Culturales, la definición de la cultura proveniente de la Antropología carece de una visión histórica política como lo denuncia Castro-Gómez:

"La noción de cultura de la antropología es incapaz de dar cuenta de un mundo producido por las fuerzas de la 'globalización' y las transformaciones en todos los planos de la experiencia social que han acabado con las 'sociedades aisladas'. Además, afirman que como habitamos un mundo cada vez más complejo e interconectado, las fragmentaciones arbitrarias de la realidad propias de las disciplinas como la antropología son epistémicamente erradas y políticamente paralizantes Para decirlos sin ambages, no son pocos en los estudios culturales que asumen que las disciplinas (y entre ellas obviamente la antropología) están mandadas a recoger y los estudios culturales en su carácter transdisciplinario (o indisciplinario, como les gusta decir a unos) son los llamados para la superación de las disciplinas" ( Castro-Gómez, 2003: 121).

Del concepto de la cultura se puede dilucidar que la Antropología acusa a los Estudios Culturales de ser una idea académica limitada que parten de "colonización intelectual" o "una nuevo eurocentrismo" desde los Estudios Culturales la Antropología es vista como un producto intelectual y académico del colonialismo. Para cerrar esta disputa no se puede dejar de lado otra crítica de Reynoso "Las definiciones antropológicas de la cultura que los estudios culturales discuten son las más arcaicas y rudimentarias, o visiones expurgadas de algunas un poco más nuevas" (Reynoso, 2000: 206). A la crítica de Reynoso se contraponen las posiciones de teóricos culturales como Hall, Grossberg, Mattelart, que son retomados 
por Rojas para argumentar la crítica a los conceptos de cultura desarrollados por los antropólogos.

"Los Estudios Culturales se plantean como un proyecto intelectual orientado hacia el cuestionamiento de las visiones elitistas de la cultura, presentes aun entonces en los análisis sobre la cultura obrera, así como hacia el replanteamiento del marxismo convencional en su análisis de lo cultural. Aun cuando nacen en Inglaterra, se dispersan rápidamente alcanzado un relativo auge en Estados Unidos, Australia y América latina, en el transcurso de tres décadas aproximadamente" (Rojas, 2011: 75).

Tanto la Antropología como los Estudios Culturales se han enfrentado por los conceptos de cultura, tal vez, no buscan una imposición de sus criterios, sino una multiplicidad de criterios y propuestas sobre la cultura en un campo dialógico propio de las Ciencias Sociales contemporáneas.

Pensar que las controversias entre Antropología y los Estudios Culturales se concentran en buscar una definición sobre cultura, como el único epicentro de tensiones, es decir, acabar el debate y dejarlo en una esfera muy superficial. También ha sido cuestión de debates, el concepto de poder, no obstante, diversos teóricos de las dos posiciones han tomado como punto de referencia para discutir esta categoría de poder a autores como Marx, Gramsci, Foucault y otros, donde los conceptos de hegemonía, ideología, entre otros, han sido claves para el desarrollo de sus postulados.

Este acercamiento demuestra que las diferencias por más profundas contienen ciertos parámetros de acercamiento. En esta línea es interesante la propuesta de Restrepo, que considerando su formación de antropólogo con especialidad en estudios culturales describe "la antropología contemporánea ha elaborado y problematizado algunas conceptualizaciones de la cultura en direcciones bien cercanas (y en ocasiones teniendo en cuenta los aportes de autores de estudios culturales)" (Restrepo, 2009: 19). Pero también, no hay que olvidar que, los estudios culturales han tomado prestado de la antropología ideas, conceptos y metodologías para explicar determinados hechos sociales o el propio concepto de cultura. Luego de esta parafernalia, concentrémonos en la parte medular del trabajo sobre las apropiaciones y producción de los estudios culturales en Ecuador.

\section{Tercer contacto: pensando los estudios culturales desde el Ecuador}

Los Estudios Culturales en el Ecuador tienen en la Universidad Andina Simón Bolívar el centro más importante, por no decir el único, en el Ecuador. Con una trayectoria de 14 años. Los Estudios de la Cultura en dicho centro se dividen en una maestría que se encuentra compuesta por cuatro menciones:

1.- Artes y Estudios Visuales.- Enfocada a un estudio crítico de la visualidad en la Subregión, busca reflexionar las dinámicas de producción, circulación y consumo de sentido, en el entorno visual. Toda esta escenificación esta matizada por los estudios decoloniales.

2.-Comunicación.- La cultura y las matrices comunicacionales conforman el núcleo duro de esta mención, es decir, como se construye la llamada "sociedad de masas". También recobran importancia temas como la imagen, las nuevas sensibilidades, las tecnologías de la información, culturas juveniles, entre otros temas de interés regional. 3. -Literatura Hispanoamericana.- Permite una comprensión de la literatura como lugar de representaciones de lo público, la construcción de imaginarios nacionales que han configurado las prácticas cotidianas de las naciones latinoamericanas.

4.- Políticas Culturales.- Posee un enfoque interdisciplinario, crítico y político de los estudios sobre los procesos culturales, busca un nexo reflexivo sobre las dinámicas, prácticas 
y expresiones culturales en América Latina.

En las características del programa hay una marcada incidencia de la multidisciplinaridad, partiendo de una nueva lectura, o una relectura de las teorías clásicas, desde un enfoque mucho más regional andino.

"El Programa busca que sus estudiantes se familiaricen con el debate cultural contemporáneo, la relectura de nuestros clásicos, los diversos sentidos que ha cobrado el concepto de lo andino, los planteamientos posestructuralistas y las expresiones ligadas a la religiosidad, la fiesta y la cultura populares, tomando en cuenta la presencia específica del mundo andino en el ámbito latinoamericano. A través de los aportes de los estudios literarios, la comunicación, la historia, el pensamiento latinoamericano, la interculturalidad, las artes y los estudios visuales, este Posgrado se fundamenta en una perspectiva multidisciplinaria de reflexión y análisis del campo cultural latinoamericano, constituido por una pluralidad de textos, saberes, imágenes, prácticas y relaciones culturales, a través de los cuales una heterogénea gama de actores sociales construye sus identidades y desarrolla su vida cotidiana" (Universidad Andina Simón Bolívar, 2012: 1).

Cuando se instaura la maestría en Estudios Culturales, tanto la cultura, sociedad y política ha tenido una nueva esfera para el debate, la constitución de este escenario se dio en un ambiente político ecuatoriano convulsionado, donde las Ciencias Sociales necesitaban un giro radical y necesario para reflexionar los cambios que se comenzaban a producir en el país. Catherine Walsh describe esta necesidad de una manera clara.

"La Universidad Andina Simón Bolívar, Sede Ecuador, ha venido construyendo, el uso de 'estudios culturales' no fue, ni tampoco es casual. Refleja una urgencia cada vez más evidente en los países andinos de nombrar: un campo intelectual dirigido al renovado pensamiento crítico inter y transdisciplinar; las relaciones íntimas entre cultura, política y economía; y lo que Mignolo (2000) denomina las epistemologías fronterizas -incluyendo aquellas promovidas por los movimientos indígenas y afros" (Walsh, 2003: 13).

En este sentido, la constitución en Ecuador de los Estudios Culturales, ha permitido crear una corriente teórica en contra de una academia hegemónica, que ha sido abiertamente disciplinar y reguladora sobre los saberes latinoamericanos. La mayoría de esta academia ha provenido de Europa y de Norteamérica, lo que Enrique Dussel ha denominado "eurocentrismo".

En lo referente al Doctorado existe una peculiaridad en la UASB, la presencia de dos campos de pensamiento como son los Estudios Culturales Latinoamericanos y los Estudios Latinoamericanos, donde parece ser que las líneas divisoras epistemológicas tienden a confundirse. Las características expuestas por la UASB en el primer doctorado describen a este programa como:

"El Programa de Doctorado en Estudios Culturales Latinoamericanos propone una exploración crítica y transdisciplinaria, desde la región, para ampliar los límites tradicionalmente asociados con los estudios sobre la cultura y las estructuras de conocimiento en América Latina, a partir de la noción de que en el espacio cultural confluye lo epistémico, lo étnico, lo popular, lo político y económico, el género, la clase, lo estético y lo literario, además de los asuntos de diferencia, subalternidad, representación y poder, y los significados 
y relaciones sociales que se producen y reproducen al nivel local, nacional, transnacional y global. De esta manera, la cultura es vista como un campo de enfrentamiento simbólico, y de lucha por el control de significados y de negociación del poder social. El programa, ahora en su tercera convocatoria, pretende desarrollar, desde un pensamiento crítico renovado, nuevas maneras de analizar y comprender los problemas actuales de América Latina, tomando en cuenta la heterogeneidad, la modernidad, la colonialidad, la interculturalidad y la integración, como propuestas necesarias, y la globalización, una realidad ya no sólo impuesta sino también localizada" (Universidad Andina Simón Bolívar, 2012: 1).

El campo de accionar está influenciado por categorías como la subalternidad, representación y poder; y los significados y relaciones sociales resaltado la colonialidad. El segundo doctorado se caracteriza por:

"El doctorado en Estudios Latinoamericanos busca formar investigadores avanzados que, desde el campo del diálogo interdisciplinario de las ciencias sociales, creen conocimiento original y comparativo sobre las relaciones políticas, económicas, sociales y culturales que actúan en el desarrollo de América Latina. El Programa está dirigido a profesores e investigadores que han completado una maestría en ciencias sociales, ciencia política, estudios latinoamericanos o relaciones internacionales, que cuentan con un acumulado de experiencia en investigación y enseñanza, y que han optado por un esfuerzo académico de larga duración” (Universidad Andina Simón Bolívar, 2012: 1).

Estos dos doctorados no están en disputa sobre el conocimiento ni prácticas, sino que poseen visiones diferentes. El primero se sitúa más en la esfera del reconocimiento, en el plano cultural, de los modelos de pensamiento de grupos subalternizados, como ejemplo la Universidad posee el Fondo de estudios para los Afroecuatorianos. No olvidemos que uno de los ejes temáticos del doctorado es precisamente la subaltenidad y lo decolonial. En este sentido, la directora del programa describe los núcleos centrales del debate.

"De manera específica y con relación al proyecto del doctorado en Estudios Culturales Latinoamericanos de la Universidad Andina Simón Bolívar, esta descripción-definición amplia va tomando rastros concretos. Al respecto, podemos identificar tres que sobre saltan como distintivos: lo intercultural, lo inter-epistemico y lo decolonial" (Walsh, 2010: 220).

Es decir, autores como Said, Spivak, Mignolo, Fanon, Bhabha, entre otros. Acercándose al concepto de subalterno, este es retomado desde la obra de Antonio Gramsci que constituye un punto de partida para la creación de los estudios de la subalternidad. El subalterno es un sujeto producido dentro de una hegemonía elitista, es decir, se inscribe en la lógica de una sociedad jerarquizada y desigual.

En lo que se refiere a los decoloniales, retómenos las ideas de Pajuelo, que ha trabajo en Ecuador. "El surgimiento de la poscolonialidad, como reflexión y como condición contemporánea, fue el resultado del "cruce de la historia moderna europea con las historias contramodernas coloniales" (Pajuelo, 2001: 2). Es en esta idea de la reflexión en que se sustenta el doctorado, el de cruzar y transgredir las fronteras del conocimiento.

“Aquí nuestro interés es, por un lado, evidenciar los pensamientos, prácticas y experiencias que tanto en el pasado como en el presente, se han esforzado por 
desafiar la matriz colonial de poder y dominación, por existir a pesar de ella, en sus afueras y hasta en su interior [...]. Dentro de nuestro proyecto, lo decolonial no pretende establecer una nueva línea o paradigma de pensamiento sino una comprensión críticamente-consciente del pasado y presente que abre y plantea interrogantes, perspectivas y caminos por andar" (Walsh, 2010: 221222).

En la cuestión del Doctorado en Estudios latinoamericanos, ofertados por la Universidad y su diferenciación con el de Estudios Culturales Latinoamericanos, es que posee un mayor nivel de comprometimiento con la política de intervención nacional y regional, este nivel de incidencia se lo evidencia en sus planes de estudio: campo Poder y política doméstica, campo Orden global, campo Desarrollo y ambiente, fundamentos de la investigación.

Estos han sido los caminos que han tenido que tomar la Antropología y los Estudios Culturales en el país, camino nada fácil si se considera que en Ecuador hacer Ciencias Sociales, es cada día más difícil.

\section{Telón de fondo: a manera de conclusión}

Pensar que las controversias entre Antropología y los Estudios Culturales se concentran en buscar una definición sobre cultura como el único epicentro de tensiones, es acabar el debate y dejarlo en una esfera muy superficial.

Autores como Said, Martín-Barbero, Escobar, García-Canclini, entre otros son comunes escucharlos tanto en FLACSO como en la Andina. Para finalizar, se podría argumentar que tanto la Antropología como los Estudios Culturales, tienen más coincidencias que diferencias, solo que muy pocos quieren notar tales similitudes, sobre todo de orden teórico. El camino es largo en Ecuador, pero existen dos instituciones que guardando las diferencias han fortalecido esos dos campos se saberes y eso es algo que no se puede desmerecer, pese a los cuestionamientos mutuos.

Y Colorín colorado, este cuento se ha acabado. O no.

\section{Bibliografía}

ANDRADE, Xavier

2003 “Antropología y Estudios Culturales, desmitificando oposiciones banales”, en Des/tiempo, 6: 12-19.

AUZA, María Alejandra

2012 Ficciones y realidades de los estudios culturales. Quito: FLACSO.

BEVERLEY, John

2008 "Estudios culturales y vocación política", en Nelly Richard (Comps.), Debates críticos en América Latina: 71-85. Santiago: Arcis.

CASTRO-GÓMEZ, Santiago

2003 "Apogeo y decadencia de la teoría tradicional. Una visión desde los intersticios", en Revista Iberoamericana Organización de Estados Iberoamericanos, http: //www.oei.es/salactsi/castro2.htm (23-05-2011).

DEGREGORI, Carlos Iván

2007 "La antropología en el Perú: del estudio del otro a la construcción de un Nosotros diverso". Revista Colombiana de Antropología (Bogotá), No 43, enero-diciembre: 299-334.

GROSSBERG, Lawrence

2010 Estudios Culturales. Teoría, política y práctica. Valencia: Letra Capital.

JAMES, Clifford

1995 Dilemas de la cultura. Antropología, literatura y arte en la perspectiva posmoderna. Barcelona: Gedisa. 
GARCÍA, Fernando

2011 "La construcción del pensamiento antropológico ecuatoriano: derroteros y perspectivas", en Revista Alteridades, 21, 41, http: //redalyc.uaemex.mx/redalyc/pdf/747/74721474006. pdf (17-06'-2011).

KROTZ, Esteban

2011 "La enseñanza de la antropología propia en los programas de estudio en el Sur. Una problemática ideológica y teórica”, en Revista Alteridades, 41: 19-38.

MATTELART, Armand; NEVEU Eric

2002 Introducción a los estudios culturales. Barcelona: Paidós.

MATO, Daniel

2002 "Estudios y otras prácticas intelectuales latinoamericanas en cultura y poder", en Daniel Mato (Comp.), Estudios y Otras Prácticas Intelectuales Latinoamericanas en Cultura y Poder. 21-46. Caracas: Universidad Central de Venezuela.

MIGNOLO, Walter

2003 "Las humanidades y los estudios culturales: proyectos intelectuales y exigencias institucionales", en Catherine Walsh (coord), Estudios culturales latinoamericanos. Retos desde y sobre la región andina. 31-57. Quito: Abya-Yala- UASB.

PAJUELO, Ramón

2001 "Del "poscolonialismo" al "posoccidentalismo": una lectura desde la historicidad latinoamericana y andina", en Comentario Internacional Universidad Andina Simón Bolívar, 2: $1-15$.

RESTREPO, Eduardo

2012 Estudios culturales latinoamericanos seminario 1215, Red de Estudios y Políticas Culturales. Buenos Aires, CLACSO-OEI.

REYNOSO, Carlos

2000 Apogeo y decadencia de los estudios culturales: Una visión antropológica. México: Gedisa.

2008 Corrientes teóricas en Antropología: perspectivas desde el siglo XXI. Buenos Aires: Editorial y Librería SB.

RICHARD, Nelly

2005 "Globalización académica, estudios culturales y crítica latinoamericana", en Daniel Mato (coord.), Estudios Latinoamericanos sobre cultura y transformaciones sociales en tiem-

ROJAS, Alex pos de globalización. 455-479. Buenos Aires: CLACSO.

2011 "Antropología y Estudios Culturales en Colombia. Emergencias, localizaciones, desafíos", en Revista Tabula Rasa, 15: 69-63.

SZURMUK, Mónica; MCKEE Robert

2009 "Los estudios culturales en programas de postgrado en América Latina: propuestas pedaTRIGO, Abril gógicas y metodológicas", en Revista Tabula Rasa, 10: 49-75.

2003 "Los estudios culturales latinoamericanos hacia el siglo XXI", en Revista Iberoamericana, 49: 324-325.

WADE, Peter

2010 Los estudios culturales serán la muerte de la antropología. Popayán: Universidad del Cauca.

WALSH, Catherine

2003 “Qué saber, qué hacer y cómo ver? Los desafíos y predicamentos disciplinares, políticos y éticos de los estudios (inter)culturales desde América andina", en Catherine Walsh (coord.), Estudios culturales latinoamericanos. Retos desde y sobre la región Andina.18-33. Quito: Universidad Simón Bolívar-Ediciones Abya-Yala.

2010 "Estudios (inter)culturales en clave de-colonial”, en Revista Tabula Rasa, 12: 209-227. 